\title{
Scientific Validity of Approaches to Solving a Number of Agricultural Problems in Azerbaijan
}

\author{
AM Jafarov and Aliev $\mathrm{ZH}^{*}$ \\ Institute of Soil Science and Agrochemistry of the National Academy of Sciences of Azerbaijan, Azerbaijan
}

*Corresponding author: Aliev ZH, Institute of Soil Science and Agrochemistry of the National Academy of Sciences of Azerbaijan, Azerbaijan

\begin{tabular}{|c|c|}
\hline ARTICLE INFO & ABSTRACT \\
\hline $\begin{array}{l}\text { Citation: AM Jafarov, Aliev ZH. Scientific } \\
\text { Validity of Approaches to Solving a Number } \\
\text { of Agricultural Problems in Azerbaijan. } \\
\text { Biomed J Sci \& Tech Res 24(5)-2020. BJSTR. } \\
\text { MS.ID.004102. } \\
\text { Keywords: Soil Types; Erosion Processes; } \\
\text { Pastures and Hayfields; Degradation; } \\
\text { Irrigation Systems; Vegetation Cover; Wash } \\
\text { Limit; Erosion Base Depth }\end{array}$ & $\begin{array}{l}\text { The Republic of Azerbaijan, which translates into a physically geographical area, } \\
\text { a way to the eastern part of the Caucasus, where the Big and Small Caucasus, Tallinn } \\
\text { Region, Kurinskaya oblast and Nakhichevan. The Republic is } 86.6 \text { ths. per km² or } 40 \% \\
\text { of the landfill make up the oil, } 60 \% \text { of the landfill and snow. he small Caucasus and its } \\
\text { lowlands, the complex geographical location of Azerbaijan's historic lands, have been } \\
\text { inhabited for thousands of years and have been used extensively in agriculture and } \\
\text { livestock. The complexity of the natural conditions here and the ineffective activities of } \\
\text { people have led to increased anthropogenic pressures and exogenous processes, which } \\
\text { have led to catastrophic erosion processes that have developed and developed. The } \\
\text { results of the soil-erosion study conducted in the occupied territories of the region (2004- } \\
\text { 2012) show that all types of erosion, including surface, linear, silt, grass, as a result of } \\
\text { the complex geological and geomorphological situation of the Karabakh region and the } \\
\text { combined impact of anthropogenic pressure. wind and military erosion have developed } \\
\text { in a wide range and are measured by the following average statistics. Goranboy- } 40.9 \% \text {; } \\
\text { Tartar - } 45.0 \% \text {; Aghdam - } 31.3 \% \text {; Barda - } 23.2 \% \text {, Yevlakh - } 26.4 \% \text {; Kelbajar - } 52.4 \% \text {; } \\
\text { Beylagan - } 19.8 \% \text {; Aghjabadi - } 15.7 \% \text {; Fizuli - } 45.7 \% \text {; Gabriel - } 63.3 \% \text {; Zinc - } 57.7 \% \text {; } \\
\text { Qubatly - } 44.0 \% \text {; Lachin - } 48.0 \% \text {; Serum-20.9\%; Upper Karabakh - } 37.0 \% \text {, which means } \\
\text { that } 884,000 \text { ha of agricultural land is in danger of being out of crop rotation. }\end{array}$ \\
\hline
\end{tabular}

\section{Mini Review}

Due to the fact that they have been eroded due to surface, linear and irrigation erosion characteristic of slopes, they have been lost due to the fact that the fertility of these lands has been lost. There is a risk of undesirable desertification and landslide. Particularly important in preventing these are the methods of progressive cultivation, including terraces, planting strips, application of alternate planting systems, phytomulatory measures, including perennial plants and grasses, grasses, corn and weeds.), it is undeniable that the use of organic and inorganic fertilizers at optimal rates and proportions, as well as the inevitable natural moisture deficit in the study area, is inevitable by the use of advanced irrigation methods. The slowdown in the development of the state has, in essence, been chosen by its relevance in terms of the theme and is driven by the demands of the day.

Natural grass ecosystems here are used in foothills and mountains as pastures and hay meadows and are very important

for the economy of the republic. About $70 \%$ of these forage lands have degraded due to overgrazing and depletion of forage plant species. For economic reasons, the village pastures are actually used all year round, which leads to their degradation. This situation is extremely negative, since these pastures should be used during a critical shortage of feed in the winter [1]. The rational use of mountain pastures and hayfields is the main condition for obtaining high productivity in animals while improving land. Unfortunately, in the mountain's pastures are not used for pasture rotation, developed taking into account the biological characteristics of the mountain vegetation cover, for sowing grass in areas beaten by cattle overload, for fertilizing, etc. The aim of this study is to investigate surface runoff and washing in widespread washedup soils in the country as an urgent soil erosion study in terms of optimal cultivation conditions for arable land, and to determine the suitability of existing soil characteristics. 


\section{Ecology of Mountain Forests}

The country's forest cover is $0.9 \%$ of the world's forest cover (18.5 Russian Federation, Canada), 0.11\% of Brazil. The geographical and environmental factors that are part of the forest play an important role in nature.

Clean and calm forests, springs, water resources fill the sediment with contaminated river water, and prevent and prevent flooding events. Compared with other countries, more than $11.4 \%$ of the territory of the country is represented by low-lying trees covered with forests. At the same time, it should be noted that at present, 261 hectares of forest, army, and their occupation by Armenian aggressors under the control of our territory. Although a small area, it is rich with trees and shrubs. Here more than 450 wild trees and shrubs grow. 70 of them are endemic species that do not grow elsewhere in the country. Despite the destruction of forests all over the world, the church is full of agricultural crops and pastures have been turned into forests, with large areas under fire. At present, the planet will complete the process of forestation. At the local, regional and global level, deforestation has a negative impact on biodiversity of flora and fauna, contributes to the sustainability of cloud biosphere, flood, flood and water erosion, strong winds and desertification. Mountain forests of the Caucasus and the Lesser Caucasus and Talysh mountains remained.

These forests cover more than $90 \%$ of the country. Each of these regions has its own peculiar features. Deforestation and environmental factors play a major role in mountain formation. Climbs above sea level, changing climate (temperature, rain and humidity) and soil fertility due to changes in forest composition. Prilipko 3 is divided in the country with a special emphasis on the forest zone. Low mountain forest area, according to the author, covers $800-900 \mathrm{~m}, 500-600 \mathrm{~m}$ above sea level. Our studies have shown that the Balakan region to the west of the Greater Caucasus Mountain Forest starts at $350 \mathrm{~m}$. High mountain forest zone, which combines $1800-1900 \mathrm{~m}$ at $900 \mathrm{~m}$ above sea level. It is dominated by mixed forest forests of purely peanut and fesel origin. More than 1800 meters above sea level, the mountain forest area occupies a percentage of the lower alpine zone. In many places the boundaries of the natural climate of the forest have been artificially lowered and sometimes destroyed, over 1900-2100m above the forest area. The eastern zone of the dominant oak tree species. In addition, mulberry, peanuts, maple, mountain cattle, black leather, conifers, etc. can be found. Since ancient times, people have used the forest resources to meet their needs. However, simple ways to change the process, including the nature of that time and the interference of natural complexes of the forest, were very slow.

Assessment of the State of Water and Land Resources of Azerbaijan: The total area of the republic is 8641500 hectares of land, of which 55 percent of it, i.e. 4756500 ha, is made up suitable for agriculture. or 16.6 percent of the total area, or 1,432,600 ha, is irrigated land. 1808400 hectares of the total land balance is arable land suitable for agriculture. It should be noted that 181600 hectares of the available total area of arable land are under the occupation of second-hand Armenian aggressors. 224700 hectares of arable land, perennial crops, 117600 hectares of hayfields, pastures of 2560.0 thousand hectares, 45.7 hectares of fallow areas. In the country of yards, 258,100 ha $(227,600$ ha of arable land), 1038,800 ha are part of the forest plantation areas. In connection with the increase in the population, now numbering about 10 million people, using land outside agricultural projects and allocated for the construction of individual buildings and structures, strongly developed certain types of soil erosion, and on the other hand, rising groundwater level as a result of rising to sea level rise, improper management of land reclamation measures of production areas in individual farms, violation of the rules without ecologically hazardous cultivation technology ulturum, and agricultural machinery, the area of arable land per capita is reduced year by year [1-3].

If allocated to the share of one person in 1959 amounted to 0.36 hectares of arable land, this figure was 0.23 in 1970 ha, in 1979 0.21 ha, while at the same time in 2006 it decreased to 0.155 ha [4]. $60 \%$ of the territory of the whole territory is located in the upland part of the republic. Due to the influence of natural and anthropogenic factors here, it is possible to meet in all types of erosion [5]. According to the results of our numerous studies in the field of studying the patterns of development of land degradation problems, as well as lanthtafts in some regions, it was found that the erosion process is very widespread (especially in mountainous areas) in the country. Currently, more than $42.8 \%$ of the entire territory of the republic, $70-85 \%$ in some regions suffer from various degrees of erosion [5,6]. One of the biggest factors in water and irrigation erosion.

Dominant in the republic for irrigation with furrows and inflows, agrotechnical measures, regardless of any protection of land, agriculture, horticulture and animal husbandry, cause soil erosion $[2,7]$. However, the country is facing acute water shortages.

The country's water resources are 32.5 billion m3. In dry years, this figure is reduced by 23.16 billion. $\mathrm{m} 3$. The volume of water resources in the country spend only $30 \%$, and the remaining $70 \%$ of the flow through neighboring countries [3]. It should be noted that in conditions of constant water shortage, a sharply uneven distribution of water in the country, despite the economic and environmentally efficient irrigation of crops, is not primitive, traditional or torrential, carried out by irrigation. The results of the study revealed that up to $96 \%$ of the irrigated land is watered mainly by traditional irrigation methods (furrows and inlet) by surface methods and the rest up to $5 \%$ - while in the irrigated fields it is watered using progressive water-saving low-intensity irrigation systems. Therefore, in the fields, the groundwater level rises every day. In fact, in some areas, groundwater, arable land, suitable about 1000 thousand hectares were subjected to salinization, which caused a particular danger in violation of the country's ecological balance. 
Currently, more than 53 thousand hectares of cultivated areas of the Kura-Araksin lowland endured great danger as highly saline soils according to the flood results, where household plots of the population of these regions of Azerbaijan left the crop rotation, where thorough washing of those soils from life-threatening salts of various kinds is required $[2,3,6]$. The results of monitoring studies revealed comparative indicators for water availability, of 3 Transcaucasian states: Georgia, Armenia and Azerbaijan, a follower of water resources of 70, 25 and 10 billion $\mathrm{km} 3$, respectively. The annual per capita water resources in these countries are as consistent $11,000,3,000$, and 1,500 m3 / person. According to a study in 2020, the annual water resources per capita of Azerbaijan, in turn, are 2 times less than in Armenia, and 7 times less than in Georgia. It is believed that water resources are very important in the development of the economy of each country, especially in the industrial-production sphere, and in agriculture is a key element of life.

\section{Degrees of Soil Destruction by Erosion and Methods for its Control in Azerbaijan}

\section{Degree of Soil Destruction Erosion:}

1) Grade 1: Slight erosion - occurs mainly in the form of a surface wash invisible to the eyes. ITS traces, in the form of small potholes and sediments, are easily aligned in the process of agrotechnical processing of soils.

2) Grade 2: Moderate erosion - manifests itself in the form of potholes, changes the level of humus in the soil, reducing its amount, and worsens the physicochemical properties of soils. This process does not affect the formation of the relief.

3) Grade 3: Medium erosion - intensively destroys the passive-humus layer, reaching even the mother rock. Potholes and grooves are numerous, deep and not amenable to correction as a result of the processing process, resulting in the formation of undulations of the slopes.

4) Grade 4: Severe erosion - destroys the entire soil profile, potholes and grooves are formed, entering more and more deeply into the layer of the parent rock. As a result, the so-called erosion landscape appears with a characteristic dissection of the soil cover and the formation of ravines.

5) Grade 5: Very strong erosion - erodes the entire soil profile, along with part of the foot. This leads to severe fragmentation of the soil cover, the creation of a dense network of ravines, and to the transformation of agricultural land into waste land.

\section{Degree of Soil Destruction by Wind Erosion:}

1) Grade 1: Slight erosion is caused by slight blowing from the soil of the best and most valuable colloidal, clay and dust particles. Blowing it practically does not affect the condition of the soil;
2) Degree 2: Moderate erosion already begins, to some extent, to limit soil humus due to the blowing of a large number of mineral and organic components, compared with weak erosion.

3) Grade 3: Medium erosion can significantly reduce the humus content due to the significant amount of mineral and organic particles and cause damage to crops.

4) Grade 4: Severe erosion leads to changes in soil profile. These soils are subject to strong blowing, have a clearly reduced level of humus, which accumulates in wind deposits.

5) Grade 5: Very strong erosion leads to the formation of dunes. Heavily eroded lands must be completely covered by forests.

Such ideas became the basis for the development of a program to protect land from erosion degradation for the whole country. Large-scale accounting was carried out only in those places for which plans or projects for the development and organization of the economy are being developed. This model does not account.

\section{Research Methodology}

Degree of Soil Destruction by Wind Erosion: In order to study the areas of distribution and the intensity of the development of erosion processes, we used field and laboratory research methods. The phenomenon of soil erosion and the areas of its distribution were described comparatively-geographically, stationary and semi-stationary methods. The decisive role of the terrain in the manifestation and development of soil erosion is well known. The most pronounced factors of the nature of mountain regions are the surface slope, the depth of local bases and the exposure of the slopes. Therefore, on the basis of topographic maps on a scale of 1: 50,000, a map of the same name erosion factors for the study area was compiled. When compiling a map of surface slopes, the following gradations were adopted: $0-30 ; 3-50 ; 5-70 ; 7-100 ; 10$ $150 ; 15-200 ; 20-250 ; 25-300 ; 30-450$; and more than 450 . For the distribution of land along surface slopes, we used the indicators of the average weighted value of slopes proposed by M.N. Zaslavsky (1979)

$$
Z h s r . v z v=\frac{i_{1} s_{1}+i_{2} s_{2}+\ldots \ldots+i_{n} s_{n}}{100}
$$

where Zh.sr.vzv - average weighted value of slopes

I1; and 2; in - bias of the allocated contours,

C1; c2; sn - the area of the allocated contours, $\%$ of the total area.

A depth map of local erosion bases was compiled to determine the excess of watersheds over riverbeds and their tributaries, as well as large ravines and depressions. To compile this map, the following gradation was adopted: $0-50 ; 50-100 ; 100-150 ; 150-200$; 
200-250; 250-300; 300-400; 400-500 and more than 500m [5]. The map of the slope exposition was compiled on a topographic basis and highlighted: northern, northeastern, northwestern, eastern, southern, southeast, southwest exposure. When conducting soil erosion studies, the classification of S.S.Sobolev was used (a description of which is given in the book of I.F. Sadovnikov 1954). Given this classification, soils according to degree of erosion were distinguished as follows:

1) Unwashed soils - There are all genetic horizons, destruction is not observed;

2) Weakly washed soils - No more than half of the humus horizon A is washed out, formation of streaky erosion is observed on the soil surface.

3) Medium-washed soils - More than half of genetic horizon A is absent.

4) Highly washed away soils - Horizon A is completely washed away, and horizon B partially passes.

Improving the eroded soils of pastures in Azerbaijan: The territory of the Azerbaijan Republic is located in the eastern part of Transcaucasia, this includes the regions of the Greater and Lesser Caucasus, the Talysh zone, and the Kurinsky Depression. The total area of the republic is 86.6 thousand $\mathrm{km} 2$, about $40 \%$ of the land area is plains, the remaining $60 \%$ is foothill and mountainous territories. The climatic conditions of the republic are varied being a mountainous country, the republic at the same time has vast lowlands, valleys and, due to the diversity of the relief surface, has a diverse climate. The republic is protected from the invasion of cold air masses from the north by the main Caucasian ridge. Depending on the altitude, climatic conditions vary. With the rise in the mountains, the average air temperature drops. Of the 11 under the types of climate established on the Globe, we have 9 under the types of climate, there is no savannah climate and tropical rainforest climate. Typical soil types are mountain meadow soddy, further mountainous soils, gray brown in the foothills and foothill plains, gray brown in the arid zone, yellow earth in the Talysh zone. Despite the small area, the republic has a variety of natural conditions and rich natural resources. One of the natural resources in Azerbaijan is pasture. The area of pastures in the republic is $22.3 \%$ of the total area.

Summer pastures make up 621 thousand hectares, winter pastures 1.5 million hectares, village pastures and hayfields make up about 1 million hectares. It is known that the Republic of Azerbaijan has long been distinguished by the livestock industry. Our land with rich natural pastures and pastures located in the alpine zones is a natural resource. However, due to various circumstances, including soil erosion, these natural feed resources lose their potential fertility. One such circumstance is soil erosion. Erosion is destruction, erosion, as the geological term is destruction of the upper fertile soil layer under the influence of wind and water. The upper layer of the earth's crust as a result of processes occurring in nature, undergoes various changes. This process can proceed as a normal natural phenomenon, also intensively as a result of anthropogenic stress. In any of 2 cases, the topsoil is washed away. Regardless of the type of erosion, the most developed fertile upper accumulative horizon is carried away. Together with water flows and the solid phase of the soil, nutrients with a finely dispersed fraction are carried away and, depending on the degree of washing, the damage caused by erosion is different.

It should also be noted that along with water erosion, the manifestation of wind erosion - deflation - is also great. Wind erosion is intensively manifested in the arid zone, where a dry climate, enhanced wind regime, and insignificant precipitation contribute to the degradation of vegetation. The intensity of the development of wind erosion compared to water is low. However, the damage caused by wind erosion to agriculture is colossal. Wind erosion, on the one hand, contributes to the blowing of the soil, on the other hand, the accumulation of particles in the form of a hill, moving sands cover vegetable and melon crops, roads, construction sites, squally winds tear off the roofs of houses. Natural fodder land located on eroded slopes has low productivity. Scientific concept of solving various problems in Azerbaijan Argo The system of surface improvement of natural hayfields and pastures is to improve fodder land in the state of economic value by improving the water, air and food regimes, caring for the grass stand, for the longest time. Surface improvement is advisable in meadows, where $20-25 \%$ of valuable forage grasses are preserved in the grass. On hayfields and pastures with the worst grass stand, surface improvement does not give the desired effect, and a radical study should be carried out on them.

\section{References}

1. ZH Aliyev (1990) Aerospace monitoring of soil cover dynamics. Aerospace methods in soil science and their use in agriculture. M Nauka p. $55-60$.

2. BH Aliyev, AC Musayev, AA Ibrahimov (2003) Ways to increase the efficiency of farming in erosion-prone and eroded soils in the mountainous area of the Republic of Azerbaijan Baku p. 80.

3. Vinogradov BV (1984) Aerospace monitoring of ecosystems. M Nauka pp. 320.

4. AB Jafarov (2009) Agroecological assessment and grouping of pasture lands of Azerbaijan, Sat. scientific works of the Research Institute of GT and M 29th volume of Iflu, p. 133-139.

5. SS Sobolev (1959) On the spread of erosion in the European part of the USSR and on measures to combat it. Soil Science $7 \mathrm{M}$.

6. Zaslavsky MN (1963) Erosion Studies, Moscow, Higher School Publishing House pp. 212.

7. F Sadovnikov (1982) The physiology of heat and drought tolerance of plants. Improving the eroded soils of pastures in Azerbaijan. M Nauka 280: 3 . 
ISSN: 2574-1241

DOI: 10.26717/BJSTR.2020.24.004102

Aliev ZH. Biomed J Sci \& Tech Res

(C) (P) This work is licensed under Creative

Submission Link: https://biomedres.us/submit-manuscript.php

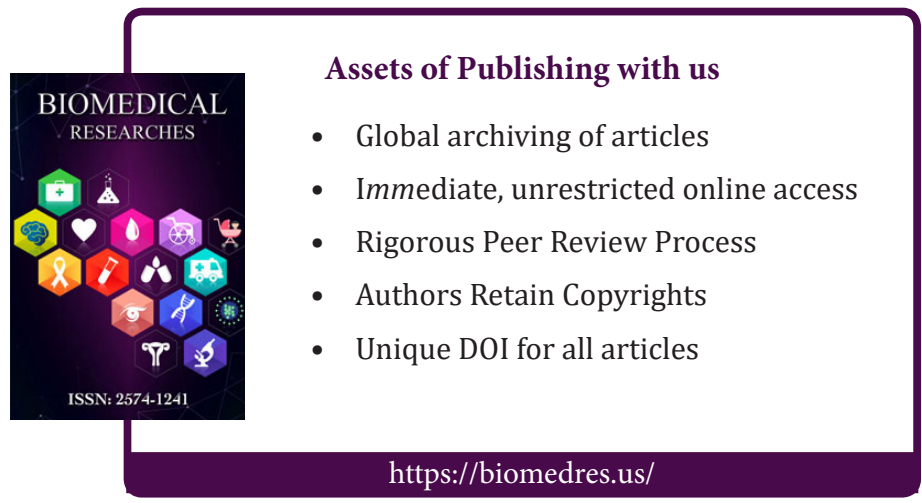

